\title{
An indicator of adverse pregnancy outcome in France: not receiving maternity benefits
}

\author{
Béatrice Blondel, Marie-Josèphe Saurel-Cubizolles
}

\begin{abstract}
Study objective-The aim was to compare the social characteristics, the pregnancy outcome, and the antenatal care of women in France who did not receive maternity benefits to women who did. These benefits (860 FF, approx $£ 86$ per month) are given to every pregnant woman, starting in the second trimester. Payments are made on the condition that at least three antenatal visits are made, the first being before the end of the first trimester.
\end{abstract}

Design-The study involved a random sample of women who were interviewed after delivery during their stay in hospital. Data on pregnancy outcome were collected from medical records.

Setting-The study was carried out in four public maternity units in different regions of France.

Participants-1692 women were included in the analysis $(86.8 \%$ of the selected sample). Of 257 exclusions, 40 had multiple pregnancies, 189 had missing data, and 28 did not answer the question concerning maternity benefits.

Measurements and main results $-4 \cdot 3 \%$ of the women did not receive any maternity benefits. These women lived in poorer social conditions than the women who received the benefits. They had a higher preterm delivery rate, after controlling for risk factors in a logistic regression. Women without maternity benefits were characterised by a lower level of care, yet the majority began their antenatal care during the first trimester or had more than six visits.

Conclusions-Not receiving maternity benefits during pregnancy is an index of an underprivileged situation and a risk factor for pregnancy outcome.

In France every pregnant woman receives a monthly grant of 860 francs (approximately $£ 86$ ), which is paid from the start of the fourth month of pregnancy and up until the child is three months old. The amount of this grant is revalued twice a year, as are all the other family benefits. The aim of the maternity benefits is to provide parents with resources at a time when there are many additional costs, and to give women an incentive to have at least a minimum amount of medical care. The grant is paid on condition that women make at least three antenatal visits: the first before the end of the first trimester of pregnancy, the second during the sixth month, and the third during the first half of the eighth month. At each of these visits, the care giver attests that the woman attended, $\mathrm{s}(\mathrm{h}) \mathrm{e}$ completes a form, and the pregnant woman sends it to the agency which manages the maternity benefits. Payment of the benefits is related to care; if a woman misses one of these three visits, payments can be cancelled for several months.

The minimum care related to maternity benefits is much lower than the standard recommended by the French obstetricians, which is around seven visits. ${ }^{1} \mathrm{It}$ is also low in comparison to the care actually received by pregnant women: in $198151 \%$ of the women received seven antenatal visits or more. ${ }^{2}$

This policy relating a minimum amount of antenatal care to substantial benefits may have an impact, in underprivileged women in particular, as inadequate care (very low number of visits or late care) is more frequent in women of low social class than in other women, ${ }^{34}$ and as women living in poor social conditions have a higher risk for having a preterm delivery or a low birthweight baby. 56

The impact of the maternity benefits on antenatal care is not very well known. Ten years ago, we found that in areas where the standards of medical care were high the link between maternity benefits and antenatal care had little influence on the number of visits; however, this link still represented a safety net in underprivileged areas where women had a low number of visits. ${ }^{7}$ At present, no national figures are available on the proportion of women who do not receive their maternity benefits and we do not know the reasons and the consequences of such situations.

In the present study, we wanted to know if the women who did not receive their maternity benefits belonged to the group expected to benefit most from this policy, ie, socially disadvantaged women and high risk women. Furthermore, we compared the pregnancy outcome of women who missed their benefits and women who received them. Finally, we studied the antenatal care received by the women in order to determine the role of missing visits in the payment of the maternity benefits. We used data from a sample of 1692 women interviewed after delivery, in local maternity units.

\section{Methods}

The survey was conducted between April 1987 and May 1988 in four public maternity units: two units were located in the suburbs of Paris, one unit was in the north, and one was in the east of France. A random sample of 1949 deliveries was drawn in the units. 
Data on social situations and antenatal care were obtained by interviewing the mother two to outcome were collected from medical records.

We excluded a total of 257 women from our study: 40 women because of multiple pregnancy, 189 women for whom data were missing because of early discharge after delivery, language difficulties, refusal or maternal handicap, and 28 women who did not answer the question concerning maternity benefits.

The social and demographic situation of each woman was characterised by age, parity, education, nationality, occupation, and cohabitation with the child's father. Women were classified as having a low level of education if they never attended school or if they left school before completing the fourth year of secondary education; generally this level of education corresponds to the end of compulsory schooling. We considered housewives, students, or unemployed women as women without occupational activity. We also considered the occupational activity of the child's father if he was living with the woman.

Two neonatal characteristics of the newborn were studied: birth weight and gestational age. Gestational age was calculated from the date of the last menstrual period. When this date was not available, we used the gestational age estimated by the hospital staff. A preterm delivery was defined as birth occurring before 37 completed weeks of gestation. were studied. The first was the total number of antenatal visits, three visits being required to get the maternity benefits, a minimum of four visits being recommended by the Ministry of Health, and about seven visits being recommended by the medical profession. This variable did not take into account the timing of the visits, so some women may have had three visits but not the three specific

Table I Proportion of women who did not receive the maternity benefits by demographic and social characteristics. four days after delivery. Data on pregnancy

The following characteristics of antenatal care

visits required for the maternity benefits. We also considered the date of the first visit, knowing that this visit had to be made before the 16th week of gestation in order to receive the maternity benefits. We also took into consideration whether the women had seen a professional qualified in obstetrics (obstetrician or midwife) at least once.

For the analysis we compared the women who received at least one payment of the maternity benefits and the women who did not receive any benefits before delivery. Comparisons were made for social and demographic characteristics of the women, pregnancy outcome, and antenatal care using Pearson's $\chi^{2}$ test. We compared maternal characteristics of the two groups adjusted for nationality because French women and women from abroad have very different lifestyles. For this comparison we used the Mantel-Haenszel $\chi^{2}$ test. In order to take into account all of the maternal characteristics related to receiving benefits we carried out a logistic regression. This method was also used to study the relationship between maternity benefits and preterm delivery, after considering the other relevant risk factors. The statistical analysis was conducted with SAS software. Data are presented as odds ratios (OR) with $95 \%$ confidence intervals $(\mathrm{CI})$.

\section{Results}

In the sample, $4.3 \%$ of the women said that they did not receive any payment of the maternity benefits before their delivery. The proportion of women without maternity benefits varied according to the demographic and social characteristics of the women. This proportion was higher in young women, grandmultiparae, foreign women, and women who were not cohabiting with the child's father (table I). A low level of education and no occupational activity in women or in the children's fathers were also associated with not receiving maternity benefits.

The relationship between maternity benefits and maternal characteristics controlled for nationality is shown in table II. In both French

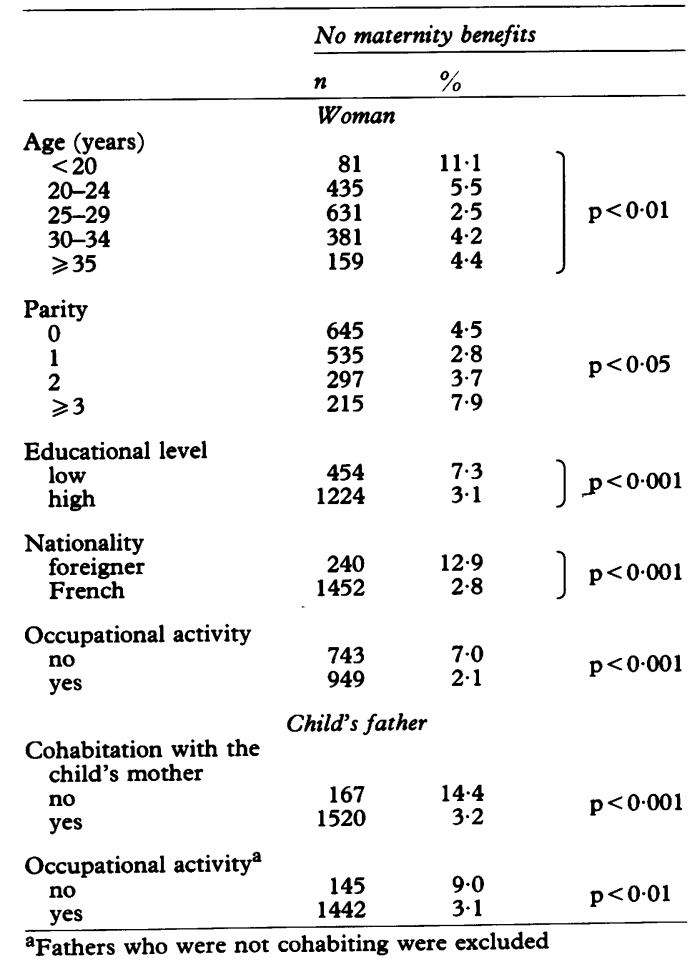

Table II Proportion of women who did not receive the maternity benefits by maternal characteristics adjusted for nationality.

\begin{tabular}{|c|c|c|c|}
\hline & $\begin{array}{l}\text { French women } \\
\text { No maternity } \\
\text { benefits } \%\end{array}$ & $\begin{array}{l}\text { Foreign women } \\
\text { No maternity } \\
\text { benefits \% }\end{array}$ & $s^{1}$ \\
\hline $\begin{array}{l}\text { Age (years) } \\
<25 \\
\geqslant 25\end{array}$ & $\begin{array}{l}(448) \quad 4.9 \\
(999) \quad 1.9 \\
\mathrm{p}<0.001\end{array}$ & 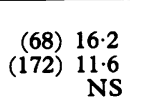 & $p<0.01$ \\
\hline $\begin{array}{c}\text { Parity } \\
0 \\
1-2 \\
\geqslant 3\end{array}$ & $\begin{array}{ll}(564) & 2 \cdot 8 \\
(735) & 2 \cdot 3 \\
(153) & 5 \cdot 2 \\
& \text { NS }\end{array}$ & $\begin{array}{rr}(81) & 16 \cdot 1 \\
(97) & 9 \cdot 3 \\
(62) & 14 \cdot 5 \\
& \text { NS }\end{array}$ & NS \\
\hline $\begin{array}{l}\text { Educational level } \\
\text { low } \\
\text { high }\end{array}$ & $\begin{array}{ll}(331) & 3.9 \\
(1116) & 2.4 \\
& \text { NS }\end{array}$ & $\begin{array}{r}16 \cdot 3 \\
\text { (123) } 10 \cdot 2 \\
\text { NS }\end{array}$ & $p<0.05$ \\
\hline $\begin{array}{l}\text { Occupational activ } \\
\text { no } \\
\text { yes }\end{array}$ & $\begin{array}{l}\text { ity } \\
\begin{array}{ll}(573) & 4.5 \\
(869) & 1.5 \\
p<0.001\end{array}\end{array}$ & $\begin{array}{r}(157) \\
(80) \\
8 \cdot 3 \\
\text { NS }\end{array}$ & $\mathrm{p}<0.001$ \\
\hline $\begin{array}{l}\text { Family status } \\
\text { not cohabiting } \\
\text { cohabiting }\end{array}$ & $\begin{array}{cc}(146) & 13.0 \\
(1301) & 1.7 \\
\mathrm{p}<0.001\end{array}$ & 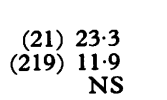 & $\mathrm{p}<0.001$ \\
\hline
\end{tabular}


and foreign women, the proportion of women who did not receive the maternity benefits was higher when the women were young, when they had a low educational level, when they had no occupational activity, or when they were not cohabiting with the child's father. Differences were not always significant in the subgroups but, on the basis of the overall tests, we found a significant relationship between the receipt of maternity benefits and maternal characteristics, except for parity, after controlling for nationality. When adjusting for each maternal characteristic, the relationship between benefits and nationality was always significant $(p<0.001)$.

When all these maternal characteristics (age, parity, educational level, nationality, occupation, and cohabitation) were taken into account, failure to receive maternity benefits was significantly related to foreign nationality ( $O R=5.5 ; 95 \%$ $\mathrm{CI}=3 \cdot 2-9 \cdot 5)$, no cohabitation (OR $=4 \cdot 8 ; 95 \%$ $\mathrm{CI}=2 \cdot 7-8 \cdot 8$, and no occupational activity ( $\mathrm{OR}=2 \cdot 1 ; 95 \% \mathrm{CI}=1 \cdot 1-3 \cdot 7)$, but it was no longer related to age, parity, and educational level.

The proportion of deliveries before 37 weeks of gestation was higher in women without maternity benefits $(18.3 \%)$ than in the other women $(6.8 \%)$ $(p<0.001)$. Birthweight was lower in the group who did not receive maternity benefits than in the other group but the differences were not significant: the mean birthweight was 3179 (SD 518) $\mathrm{g}$ in women who had not received the benefits and 3284 (513) $g$ in women who had received them $(p>0.05)$, and the proportion of babies weighing less than $2500 \mathrm{~g}$ was $9.7 \%$ and $5.6 \%$ respectively in these two groups $(p>0.05)$.

We found that women who did not receive maternity benefits had characteristics which are known risk factors for preterm delivery (table II). The relationship between the lack of maternity benefits and preterm delivery was measured while taking into account the other risk factors in a logistic regression (table III). Failure to receive maternity benefits was significantly related to preterm delivery after controlling for the other factors: $\mathrm{OR}=2 \cdot 1,95 \% \mathrm{CI}=1 \cdot 1-4 \cdot 2$.

Table IV shows that antenatal care was less important in the group without maternity benefits

Table III Adjusted odds ratios of preterm delivery with $95 \%$ confidence intervals (CI) (logistic regression analysis).

\begin{tabular}{llll}
\hline & Odds ratio & $95 \%(C I)$ & $S$ \\
\hline No maternity benefits & $2 \cdot 1$ & $1 \cdot 1-4.2$ & $\mathrm{p}<0.05$ \\
Low educational level & 1.2 & $0.8-1.8$ & $\mathrm{NS}$ \\
Foreigner & 1.2 & $0.7-1.9$ & $\mathrm{NS}$ \\
$\begin{array}{l}\text { No occupational activity } \\
\text { No cohabitation with the }\end{array}$ & 1.7 & $1.1-2.5$ & $\mathrm{p}<0.05$ \\
$\quad$ child's father & 1.5 & $0.9-2.6$ & $\mathrm{NS}$ \\
\hline Number of women $=1660$ & & &
\end{tabular}

Table IV Antenatal care and receipt of maternity benefits. than in the other group. Women who had less than three visits comprised $12.9 \%$ of the group without maternity benefits and $0.3 \%$ of the other group. The proportion of women who started their antenatal care after the deadline defined by the regulation (the 16th week of gestation or later) was $35.7 \%$ and $7.3 \%$ respectively in these two groups. However, the date of the first antenatal visit was not known for $22.2 \%$ of the women without maternity benefits and $6 \cdot 3^{\circ}$ of the women with maternity benefits $(p<0.001)$. The care givers were different in the two groups: visits to an obstetrician or a midwife were less frequent in the group of women without maternity benefits than in the other respondents.

Despite the low level of antenatal care among the women who missed their maternity benefits, more than half of these women made at least seven antenatal visits. In the group of women without maternity benefits we compared the number of antenatal visits according to the maternal demographic and social characteristics. The number of visits was not related to age, parity, occupational activity, or educational level. Women who made less than seven visits cohabited less frequently $(50 \%)$ than women who made seven visits or more $\left(88^{\circ}\right)(\mathrm{p}<0.02)$ and they were more often French $\left(70^{\circ}{ }_{0}\right.$ and $48^{\circ}{ }_{0}$ respectively; $p=0 \cdot 06$ ).

\section{Discussion}

This study shows that women who did not receive maternity benefits were socially disadvantaged and they had a high preterm delivery rate. Women without maternity benefits also had a lower level of antenatal care than the other women. Nevertheless, the majority of them had made at least seven visits.

The studied population was not representative of the women who delivered in 1987 in France. The maternity units were located in large towns, their case mix was characterised by a high proportion of semi-skilled or unskilled manual workers, ${ }^{8}$ and the proportion of women under 20 years of age and foreigners was higher in our sample than in the overall population of women who gave birth in France. ${ }^{89}$ This selection may have overestimated the proportion of women who did not receive any maternity benefits, but national figures are not available to confirm this hypothesis.

Women who did not receive their maternity benefits had a higher preterm delivery rate than the other women; a shorter duration of pregnancy might give them less opportunity to get their benefits before delivery. Nevertheless, when the first antenatal visit is made on time (ie, before the 16th week of gestation) pregnant women can receive the first payment of their maternity benefits during the fourth month of pregnancy. Thus all the women who had a preterm delivery, even if it was very preterm, should have received the first payments of the maternity benefits.

Despite the fact that the policy related to maternity benefits is aimed at reducing financial difficulties and preventing adverse pregnancy outcome, the lack of these benefits was more frequent among women who lived in poor social conditions and who were at high risk for preterm 
delivery. The various reasons for not receiving any payment of the maternity benefits during pregnancy may be: no qualifications for these benefits, no claim or late claim for the benefits, or no antenatal visit or very late antenatal care.

Maternity benefits are provided for women who live in France; thus women who immigrated very recently or who are staying in France illegally are not allowed to claim these benefits. Some other women may not know of the maternity benefits or of their relationship with antenatal care. The name of the benefits and their payments have been modified since their introduction in 1953, but the conditions relating payment to antenatal care have not changed. Thus women who do not know these regulations are most likely to be socially isolated or recent immigrants, or immigrants with language difficulties. The lack of maternity benefits may be more frequent among women who have difficulties in writing letters and in understanding the process for obtaining the benefits. In France, poor social conditions also characterise people who are not reimbursed for their medical expenditure by Social Security ${ }^{10}$ because the administrative procedures which are requested are often too complicated for those such as the unemployed, homeless, or single. ${ }^{11} 12$

Since maternity benefits depend on antenatal care, social inequalities which are usually observed in the number of antenatal visits and in the delay of the first visit $^{34}$ may have repercussions on receipt of the benefits. For example, delay in confirming the pregnancy and in having the first antenatal visit may be longer in single women than in other women because of denial of the pregnancy, anxiety about confronting the medical doctor and the family, or fear of being coerced into having an abortion. ${ }^{13}$ Some other women may have missed their maternity benefits because of financial difficulties related to having antenatal care: in most places where care is provided, women must pay for the care at the time of the visit and they will be reimbursed later at 70,80 , or $100 \%$, depending on the type of care and the period of pregnancy.

Thus the lack of maternity benefits is often the result of inequalities both in the access to benefits and in the use of medical care, and could be considered as an index of very underprivileged situations.

The women who did not receive their maternity benefits had a preterm delivery rate twice that of the other women. At present the effectiveness of a large amount of antenatal care is unknown but it seems that the lack of antenatal visits is related to poor pregnancy outcome,,$^{14} 15$ and the preterm delivery rate may be two or three times higher in women without care. ${ }^{16}$ In our population, only six women had no care and, of these women, one had a preterm delivery. Some other women without maternity benefits had a very low level of care (late care or few visits), which also may have had an effect on the preterm delivery. Very poor social conditions may be another reason for the higher preterm delivery rate observed in women without maternity benefits. For women on low income, the benefits represent a substantial help in facing the extra costs of pregnancy and childbirth. They may help these women to have adequate diet, to reduce tiring living conditions, and to decrease the stress of trying to cope with too little money. We do not know what are the effects of the financial benefits on the health of either mother or child; nevertheless several studies suggest that poor psychosocial conditions represent risk factors for preterm delivery. ${ }^{17} 18$

We do not know whether this policy for maternity benefits was effective in insuring a minimum antenatal care for every woman. It may have an effect on early care since French women have their first visit very early: in $198196 \%$ had medical care during the first trimester of pregnancy (B Blondel, unpublished data). The timing of the first visit is rarely known in other countries, ${ }^{19}$ but in 1981 in the USA, $76 \%$ of the pregnant women had care before the fourth month of pregnancy and this figure has not changed since that year. ${ }^{19}$ Furthermore, 10 years ago, in an area with a low standard of medical care, we found that the women who had three or four antenatal visits were familiar with the conditions relating maternity benefits to antenatal visits. ${ }^{7}$ These results suggest that for women who do not want to or cannot have a great number of visits, the number of visits required for the maternity benefits can be a safety net to ensure a minimum level of care.

In France, the possibility of dissociating the receipt of maternity benefits and antenatal care has often been evoked. Two reasons for this are given. First, almost all women seek out medical care early on in their pregnancy, and secondly certain very underprivileged women do not receive these benefits. However, it is difficult to dissociate maternity benefits from antenatal care because every women has to send a medical certificate, proving that she is pregnant, to the organisation in charge of payments. Thus in Great Britain pregnant women send a certificate of expected confinement to apply for maternity benefits. But in contrast to the British example, the distribution of maternity benefits in France begins relatively early on in pregnancy. Therefore pregnant women should have a first medical examination within the first few months of pregnancy. This organisation seems very important in so far as one way to prevent inadequate antenatal care and a very low number of medical visits is to promote early antenatal care.

Insofar as it is difficult to separate the distribution of maternity benefits from antenatal care, a question which needs to be considered is how the number of women who do not receive these benefits can be reduced. Some women begin their antenatal care early or have numerous visits without receiving maternity benefits. Such a situation is difficult to avoid for recent immigrant women or women who are staying in France illegally, but for the others the lack of benefits could be prevented if the care providers, or the social workers in the antenatal clinics, checked whether every woman was familiar with the relationship between antenatal care and maternity benefits and whether she had taken the necessary administrative steps in order to ensure the receipt of these benefits. It seems more difficult to improve the condition of women who missed their benefits because of no care or late care. In these cases, the questions which must be considered have very little to do with the functioning of the 
benefits-antenatal care system. They are related to the situations specific to the most underprivileged women. Some of the issues which need to be examined are free medical care, appropriate behaviour of the medical staff of the antenatal clinics, education about the importance of preventive medical care, and prevention of unwanted pregnancies.

\section{CONCLUSION}

The system of maternity benefits related to antenatal care probably has the most beneficial effect for underprivileged women because these benefits substantially increase the family resources, and the system promotes medical care and thus counterbalances the social inequalities usually observed in the use of primary health care. Our results show that this objective is not completely reached.

This research was partly supported by a grant from the Caisse Nationale des Allocations Familiales (National Foundation of Family Allowances). The authors thank all the women who agreed to answer the survey, the department head and the staff of each of the four participating maternity units, the interviewers, and the persons who coded the data. We also thank Ms M Kaminski and Dr G Breart for their comments on the preliminary drafts, Ms M C Nourry for secretarial assistance, and Ms $\mathrm{K}$ Bean for reviewing the English.

1 Chartier M. Les impératifs de la surveillance de la grossesse. In: Soutoul JH, Froge $\mathrm{E}$, eds. La responsabilité médicolégale en gynécologie-obstétrique. Paris: Vigot, 1982; 41-6.

2 Rumeau-Rouquette C, Rabarison Y, Du Mazaubrun C, eds

Naître en France. Dix ans d'évolution. Paris: INSERM-
IN Daitre en Fran 1984.
3 Blondel B, Kaminski M, Bréart G. Antenatal care and maternal demographic and social characteristics. Evolution in France between 1972 and 1976. F Epidemiol Community Health 1980; 34: 157-63.

4 Garcia J, Blondel B, Saurel-Cubizolles MJ. The needs of childbearing families: social policies and the organization of health care. In: Chalmers I, Enkin MW, Keirse MJNC, eds. Effective care in pregnancy and childbirth. Oxford: eds. Effective care in pregnancy and chil

5 Kramer MS. Intrauterine growth and gestational duration determinants. Pediatrics 1987; 80: 502-11.

6 Blondel B, Zuber MC. Marital status and cohabitation during pregnancy: relationship with social condition, antenatal care and pregnancy outcome. Pediatr Perinat Epidemiol 1988; 2: 125-37.

7 Blondel B, Saurel-Cubizolles MJ, Kaminski M. Impact of the French system of statutory visits on antenatal care. 7 Epidemiol Community Health 1982; 36: 183-6.

8 Saurel-Cubizolles MJ. Mesures concernant la protection des femmes enceintes au travail: fondements, principes et réalités. Paris: Rapport d'un contrat CNAF-INSERM, 1988 (Available on request to the author.)

9 Couet C, Court Y. La situation démographique en 1987. Les Collections de I'INSEE série D 1989; 131.

10 Bourget Devouassoux B. Les exclus de la couverture maladie. Solidarité Santé 1989; 5: 29-34.

11 Strohl $H$. La couverture sociale du risque maladie: l'exclusion de fait des plus démunis. Problèmes Economiques 1988; 2091: 5-12.

12 Vincent G, Charpiot N. Lutte contre la précarité: expérience "Médecins du Monde". L'hôpital à Paris 1989; 11: 21-4. 13 Macintyre S. Single and pregnant. London: Croom Helm, 1977.

14 Wiener G, Milton T. Demographic correlates to low birthweight. Am f Epidemiol 1970; 91: 260-72.

15 Eisner V, Brazie JV, Pratt M, Hexter A. The risk of low birthweight. Am f Public Health 1979; 69: 887-93.

16 Moore T, Origel W, Key T, Resnik R. The perinatal and economic impact of prenatal care in low socio-economic population. Am f Obstet Gynecol 1986; 154: 29-33.

17 Berkowitz G, Kasl S. The role of psychosocial factors in spontaneous preterm delivery. 7 Psychosom Res 1983; 27 : 283-90.

18 Newton RW, Webster PAC, Binu PS, Maskrey N, Phillips AB. Psychosocial stress in pregnancy and its relation to the onset of premature labour. $B M \mathcal{F} 1979$; ii: $411-3$.

19 Buekens P. Variations in provision and uptake of prenatal care. Baillieres Clin Obstet Gynaecol 1990; 4: 187-205. 